\title{
Textile Contact Dermatitis: How Fabrics Can Induce Dermatitis
}

\author{
Cecilia Svedman, $M D, P h D^{1, *}$ \\ Malin Engfeldt, PhD ${ }^{1}$ \\ Laura Malinauskiene, $M D, P h D^{2}$
}

\author{
Address \\ *,1Department of Occupational and Environmental Dermatology, Skåne University \\ Hospital, University of Lund, Malmö, Sweden \\ Email: Cecilia.Svedman@skane.se \\ ${ }^{2}$ Faculty of Medicine, Institute of Clinical Medicine, Clinic of Chest Diseases, \\ Immunology and Allergology, Vilnius University, Vilnius, Lithuania
}

Published online: 8 February 2019

(C) The Author(s) 2019

This article is part of the Topical Collection on Contact Dermatitis

Keywords Textile contact dermatitis - Patch testing - Textile dye mix

\begin{abstract}
Purpose of the review Textile dermatitis can sometimes be difficult to diagnose due to the fact that it is difficult to clinically suspect, and when allergic, patch test correctly and advice the patient as to what garments to avoid.

Recent findings The textile fibres as such are rarely the causative agent. Allergic contact dermatitis due to textiles is primarily caused by substances that are used to give the material certain qualities or performances. The textile dye mix, now in the baseline series, has proven to be a useful tool in diagnosing allergic contact dermatitis but additional patch testing with own material is advocated. Future research will hopefully facilitate the diagnostic procedure.

Summary This review is a short update on textile dermatitis, both irritant and allergic, the present recommendations regarding patch testing when suspecting contact allergy and the advice to give to those allergic that will hopefully help the clinician in daily work.
\end{abstract}

\section{Introduction}

Contact dermatitis from textiles typically gives different clinical pictures, depending on whether the dermatitis is caused in the worker during the production of the textiles or in the consumer. Other important factors are the quality of garment, how it is worn and, when due to contact allergy, what the causative hapten is. Within the 
textile industry, the production process as such, in which the use of various types of chemicals seems to be ubiquitous, makes the industry a growing possible problem regarding public health as well as in the environment. From dyehouses, the wastewater discharge has serious detrimental effects on the aquatic environment. Some dyestuffs produce toxic decomposition products and the metal complex dyes release toxic heavy metals to the water. Of the dyes used in the textile industry, effluents containing reactive dyes, where considerable amounts are lost and discharged during production, are the most difficult to address $[1,2]$. When investigating possible contact allergy as causative agent, it should be remembered that some of the substances used during the production can actually be found also in the finished garments such as quinolone compounds [3-6]. In studies where occupational dermatoses have been investigated within the dye industry and textile industry, associations have been found with azo dyes in textile workers, and formaldehyde and chromate in those working in the leather and dyeing industries $[7,8]$. In the latter study, occupational allergic contact dermatitis was found associated with lesions that were primarily on the hands and wrists of the workers. Also, those selling textiles risk hand dermatitis and even widespread occupational allergic contact dermatitis has been reported amongst this group [9].

Contact dermatitis in those using the garment is often diagnosed when appearing as a chronic dermatitis, i.e., there is often a delay in diagnosis. It may be found in areas preferably with close contact between skin and textile (especially where friction or perspiration occurs), but may also be widespread $[10,11 \bullet, 12]$. However, textile "dermatitis" can also be found with no clinical morphology but symptomatic pruritus. Nummular dermatitis, and even a clinical picture of atopic dermatitis, involving flexures, is not infrequent $[11 \bullet, 13]$. The morphology of the dermatitis may differ from erythema-like or urticaria-like lesions to pigmented purpura [13].

\section{Textile contact dermatitis}

Textiles are made of fibres: natural wool, linen, cotton and silk and synthetic cellulose derivatives and polyamides. Other materials such as metal or rubber components may be added to give the textile a certain wanted characteristic, and for the same reason, the textile is further processed; textiles are coloured or prepared with different substances in order to produce specific effects or give the garment a certain quality [10]. Can the fibres per se give rise to textile dermatitis? With regard to allergic reactions to wool, both type I and type IV reactions have been reported, but these publications are usually of older date. In a recent review, Zallmann et al. [12•] found that to date, there is an absence of evidence to substantiate allergy (type I and IV hypersensitivity) to wool fibres. Furthermore, allergens associated with wool processing (e.g. chemical dyes) are present at negligible levels within modern wool garments. Cutaneous irritation caused by wool garments was previously often found and most probably due to high fibre diameters. Superfine and ultrafine Merino wool garments with finer fibre diameters seem to be much better tolerated [12•].

The same is true for cotton, where the occurrence of an immediate skin reaction to textiles is extremely rare [13]. Cotton clothing occasionally causes itchy skin or erythema, but this is usually due to skin irritation [13]. As to silk, this material has even been tried to alleviate dermatitis symptoms [14]; however, there also exist occasional case reports on immunological contact urticaria from silk exposure [15].

Textile contact dermatitis is however not uncommon [11•] and of major concern are contact allergic reactions. The major causes for allergic reactions in textiles are thus caused by how the textile is prepared and treated $[12 \bullet, 16,17]$, 
where biocides [18] have also been the cause of dermatitis. In the textile, these are used for protection during manufacture or transport and to inhibit malodour, especially, for example, in textiles used in sports. Various biocides in textiles have been reported, including triclosan, zinc pyrithione, MCI/MI, dichlorooctylisothiazolinone, dimethyl fumarate, and silver particles [19-21]. Other substances remaining after dyeing (e.g. benzanthrone, an intermediate substance used in the production of vat dyes) or treating textiles (e.g. sulfites, used during bleaching) can induce allergic contact dermatitis [22, 23]. With regard to allergic contact dermatitis to formaldehyde, urea-formaldehyde resin and melamine-formaldehyde resin, used in the textile industry since the 1920s to prevent wrinkling, have been found to be causative agents. Formaldehyde release has been documented for many fibre types [24-26], and in some countries, regulative measurements have been taken. Formaldehyde content varies in studies from different countries; wool is however suggested as a secure textile material for those sensitized [12•, 26-29].

With regard to textile dyes as causes of allergic reaction, type I reactions exist $[30,31]$ but are very rare, whereas type IV reactions are the most frequent, and therefore the focus in this review.

Table 1. Usage classification of dyes according to K. Hunger [33] with modifications by the authors

\begin{tabular}{|c|c|c|c|}
\hline $\begin{array}{l}\text { Dye class } \\
\text { according } \\
\text { to application }\end{array}$ & Main substrates & $\begin{array}{l}\text { Dye classes according to } \\
\text { chemical } \\
\text { structure }\end{array}$ & Described as allergens \\
\hline Acid & $\begin{array}{l}\text { Nylon, wool, silk (also } \\
\text { paper, } \\
\text { inks, leather) }\end{array}$ & $\begin{array}{l}\text { Azo, anthraquinone, } \\
\text { triphenylmethane, } \\
\text { azine, xanthenes, nitro, nitroso }\end{array}$ & Rare \\
\hline Azoic & $\begin{array}{l}\text { Cotton, rayon, cellulose } \\
\text { acetate, PET }\end{array}$ & Azo & \\
\hline Basic & $\begin{array}{l}\text { Polyacrylonitrile, modified } \\
\text { nylon, PET (also paper, } \\
\text { inks) }\end{array}$ & $\begin{array}{l}\text { Cyanine, hemicyanine, } \\
\text { diazahemicyanine, } \\
\text { diphenylmethane, triarylmethane, } \\
\text { azo, azine, xanthene, acridine, } \\
\text { oxazine, anthraquinone }\end{array}$ & $\begin{array}{l}\text { Rare (Basic Red } \\
\quad 46 \text {-important } \\
\text { allergen in acrylic socks) }\end{array}$ \\
\hline Direct & $\begin{array}{l}\text { Cotton, rayon, nylon (also } \\
\text { paper, leather) }\end{array}$ & $\begin{array}{l}\text { Azo, phthalocyanine, stilbene, } \\
\text { oxazine }\end{array}$ & $\begin{array}{l}\text { Rare (some cases of } \\
\text { immediate } \\
\text { type allergic reaction) }\end{array}$ \\
\hline Disperse & $\begin{array}{l}\text { PET, polyamide, acetate, } \\
\text { acrylic (also plastics) }\end{array}$ & $\begin{array}{l}\text { Azo, anthraquinone, styryl, nitro, } \\
\text { benzodifuranone }\end{array}$ & Most frequently \\
\hline Mordant & Wool (also leather) & Azo and anthraquinone & \\
\hline Reactive & Cotton, wool, silk, nylon & $\begin{array}{l}\text { Azo, anthraquinone, phthalocyanine, } \\
\text { formazan, oxazine, basic }\end{array}$ & $\begin{array}{l}\text { Described only as } \\
\text { occupational } \\
\text { allergens }\end{array}$ \\
\hline Solvent & $\begin{array}{l}\text { Plastics, fuels, varnishes, } \\
\text { lacquers, inks, oils, } \\
\text { waxes }\end{array}$ & $\begin{array}{l}\text { Azo, triphenylmethane, } \\
\text { anthraquinone, } \\
\text { phthalocyanine }\end{array}$ & Rare \\
\hline Sulphur & Cotton, rayon & Indeterminate structures & Exceptionally rare \\
\hline Vat & Cotton, rayon, wool & Anthraquinone, indigoids & Rare \\
\hline
\end{tabular}


In order to identify a possible culprit, colour identification of the agent is necessary; however, the classification of dyes is complicated since they can be classified either according to chemical structure or according to method of application. Classification according to the colour (the Colour Index, C.I.) is compiled and edited by the Society of Dyers and Colourists and by the American Association of Textile Chemists and Colorists. In the lists, there are thousands of dyes, but since every generic name covers all colourants with the same structure, they are not necessarily identical with regard to possible additives or impurities. This has also been a problem with regard to patch testing where test substances, thought to be defined, have been found to contain impurities [32].

The dye used depends on the fabric. Different colours are used for synthetic and for natural fibres (Table 1). The overall rate of sensitization to reactive dyes, used to colour natural fibres including cotton, silk and wool, is very low. In a publication by Manzini et al. [34], it was reported that 18 of 1813 patients $(0.99 \%)$ tested with the additional textile series had positive reactions to reactive dyes over 1 year. Disperse dyes (DD) are used for colouring synthetic textiles, polyester, nylon and fibre mixtures [11•] and account for $>20 \%$ of the dyes produced in the world [35]. They only partially bind to textile fibres which may explain their sensitization properties. The small, lipophilic molecules can easily migrate onto the skin especially if the textile fastness is poor [33]. Approximately $60 \%$ of all DDs are azo dyes and about $25 \%$ are anthraquinone dyes, with the remainder being quinophthalone, methine, naphthalimide, naphthoquinone and nitro dyes [35]. Azo dyes are cheap and easy to apply and can give all range of colours, making it the most common group [35]. Within the EU and by the International Oeko-Tex Association (a group of textile research and test institutes), some DDs (mainly azo dyes) are classified as allergenic, and their use is restricted [36, 37]. Contact allergy to DD dyes has long been known and different clothing have been in focus, such as, when in the 1940s-1950s, cases of reactions to nylon stockings were reported [38]. Already then, the risk of missing the allergy due to the fact that the dermatitis might mimic, for example, foot dermatitis, was raised. The allergic contact dermatitis seen in relation to DDs varies, ranging from non-pruritic erythema, especially seen with Disperse Blue 106 and 124, persistent erythematous-wheallike or transient urticarial dermatitis, to erythema multiforme-like lesions [3941]. Also, lymphomatoid dermatitis [42] and folliculitis [43] have been described. Hand dermatitis is not uncommon. Involvement of skin folds was observed in $27 \%$ of DD-positive patients, mainly comprising those sensitized to Disperse Blue 106 and 124 [44, 45]. It may thus mimic or worsen an atopic dermatitis [46]. Today, when systemic therapy is increasing in use and new drugs are introduced for patients with widespread atopic dermatitis, the need to exclude the possibility of a causative or aggravating agent in a contact allergy is increasingly important. Also, since dupilumab seems to possibly suppress the reactivity in contact allergic [47•], DDs were not initially included in any baseline series, in contrast to p-phenylenediamine (PPD), which, historically, has been considered to be a screening allergen for textile dye dermatitis. However, later reports indicate that PPD does not represent a suitable marker allergen for detecting sensitization to all azo dyes present in textiles [35]. The prevalence of DD contact allergy varies with the population and the dyes tested. In those studies [11•] in which patients were routinely patch tested and DDs were included (in total, 26 DDs were used for patch testing in 1\% pet. 


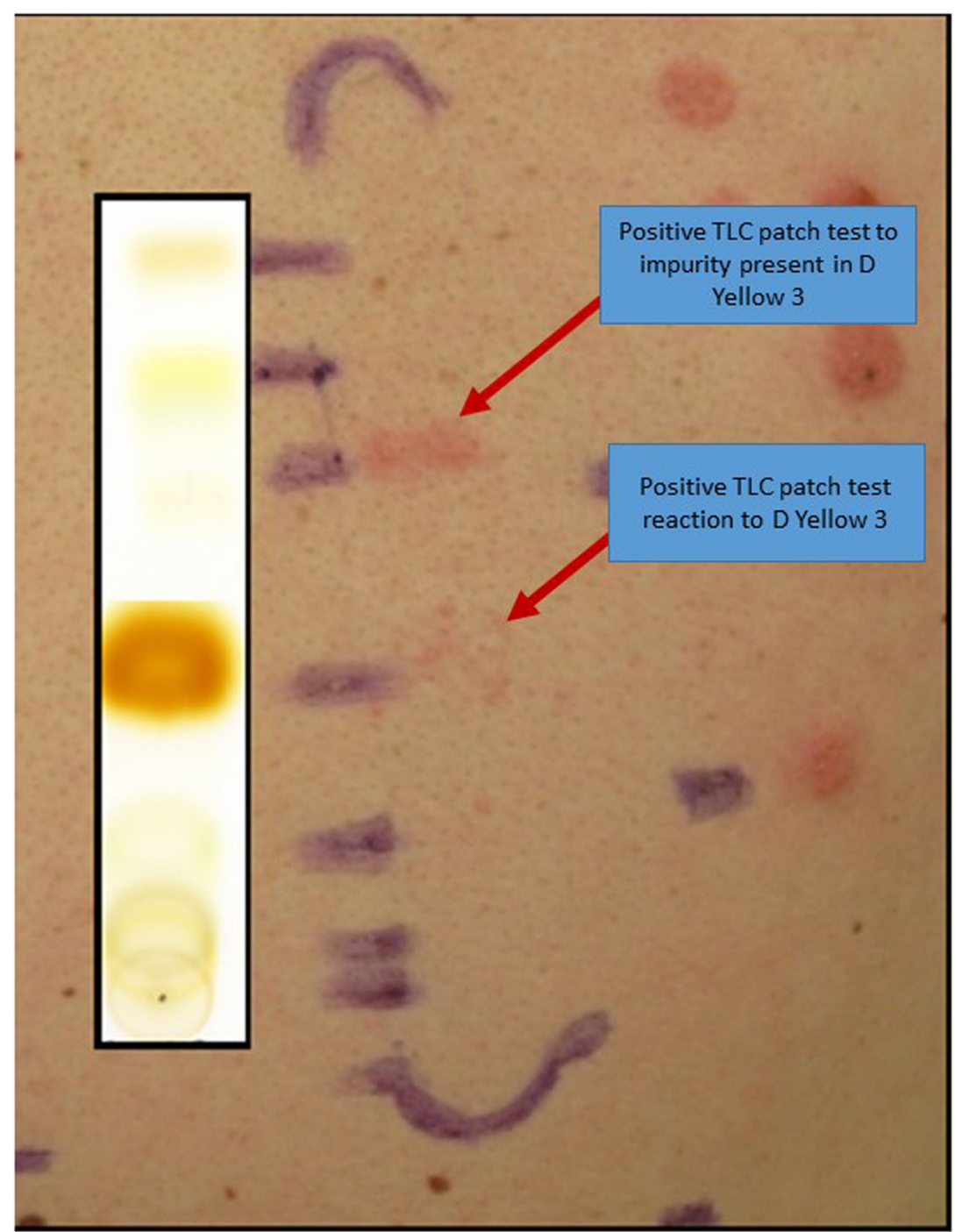

Fig. 1. Positive TLC patch test to impurity present in D Yellow 3 and positive TLC patch test reaction to D Yellow 3.

Additionally, Disperse Blue 35 was tested in $0.5 \%$ pet. and $0.3 \%$ pet., and Disperse Blue 106, Disperse Blue 124, Disperse Red 1, Disperse Red 17, Disperse Orange 1, Disperse Orange 3 and Disperse Yellow 3 in $0.5 \%, 0.3 \%$ and $0.1 \%$ pet.), prevalence values ranged from 0.4 to $6.7 \%$. DD testing in a textile dye mix (TDM) was early suggested in Portugal by Dr. Francisco Brandão (Almada, Portugal) [48•]. Starting in 1999, a TDM composed of eight DDs was introduced into the baseline series of the Department of Occupational and Environmental Dermatology in Malmö, Sweden. After publication of data from testing in Sweden $[49,50]$, it was added to the Swedish baseline series.

The mix was recommended at 6.6\% in 2015 for the European Baseline Series [48•]. The mix has also been recommended for the international baseline series [51]. The composition of the $6.6 \% \mathrm{wt} / \mathrm{wt}$ pet. mix should be as follows: Disperse Blue 35 (DB 35), Disperse Yellow 3 (DY3), Disperse Orange 1 (DO1), Disperse Orange 3 (DO 3), Disperse Red 1 (DR 1) and Disperse Red 
17 (DR 17), all at 1.0\% wt/wt, and Disperse Blue 106 (DB 106) and Disperse Blue 124 (DB 124), both at 0.3\% wt/wt [48•, 51]. With the Finn Chambers ${ }^{\circledR}$ technique, a standardised amount of $20 \mathrm{mg}$ of the pet., preparation should be used [50], corresponding to a dose equivalent to $2.2 \mathrm{mg} \mathrm{TDM} / \mathrm{cm}^{2}$.

Studies performed in Europe and the USA $[48 \bullet, 51]$ showed that $2.1-6.9 \%$ of consecutively tested dermatitis patients reacted to a $6.6 \% \mathrm{wt} / \mathrm{wt}$ textile dye mix consisting of eight disperse dyes. The clinical relevance was ascertained in $>30 \%$ of the positive cases. DO 3 and PPD had a high frequency of simultaneous sensitivity. It has even been argued that the textile dye mix within the baseline series might even be with five colours, omitting DO 3 as the impression is that these patients are actually caught by patch testing with PPD and suggestions have been made that the concentration of the mix could then actually be lower [52]. However, such consideration requires that PPD is patch tested in the correct concentration [53]. In testing with DDs, late reactions are sometimes reported, and in some studies, active sensitization has been suggested $[11 \bullet]$, while in other studies, no signs of active sensitization has been found [50]. In reports on contact allergy to DDs, there is usually a higher contact allergy rate to DDs noted in females compared to men [50]. In one study [54], a significant association was seen in females regarding contact allergy to PPD and self-reported skin problems arising from synthetic textile materials. The increased female frequency rate may be explained by a different exposure to synthetic fabrics or by the association between PPD contact allergy and allergy to DO 3 which in a large number of cases give simultaneous reactions in those sensitized [55]. From a chemical point of view, most DDs contain an azo structure. As a consequence, high frequencies of simultaneous sensitivity to DO 3 , TDM and PPD, to TDM and black rubber mix and to DO 3 and PPD $[56,57]$ are often seen.

DDs known to cause contact allergy has only infrequently been identified in clothing $[35,54,56]$. Even though DDs seem to be used rarely in clothes nowadays, when extracts from garments [56] were compared by the use of thin-layer chromatography, similar dye patterns were seen, especially in the orange, red, blue and yellow regions of the spectrum, indicating common substances other than the eight DDs. Some of these may be allergenic [36, 56]. Recently, it was shown that TDMpositive patients react to the extracts made from the textiles not containing any of the 8 DDs present in TDM 6.6\% [57]. The textile mix used today is not pure either and impurities may also explain positive reactions (Fig. 1). Therefore, even though the eight DDs included in the TDM may be used less in textiles today, the TDM is the best marker of textile contact allergy at present. For patients where textile dermatitis may be suspected, the baseline series with the textile dye mix is a major improvement. The general recommendation for patch testing when a textile dermatitis is suspected is thus the baseline series as such and supplemented with the textile series if other allergens than those in the baseline series can be suspected. When strong contact allergy to PPD and/or TDM is suspected, the tests should be placed on the arm of the patient, to facilitate early removal. The patch testing may also be supplemented with patch test of the suspected textile and extract of this. How to perform the extract has been defined elsewhere [58] and lies beyond the scope of this review. It should however be emphasised that the composition of the extract will be defined by the solvent used. A challenge test (stop and wear again) can also be used to prove allergy. The patient with a positive reaction and a dermatitis which may be explained by a textile dermatitis should be given proper information on which garments may be safe. Reading textile labels may be 


\section{Conclusions}

important although it does not contain information about chemicals used, but knowing fibre composition and care instructions can help guessing possible allergens. Any garments manufactured from cotton, wool, silk or linen are good alternatives. If polyester garments are worn, light-coloured clothes are safer than dark-coloured one.

In summary, textile contact dermatitis often looks like endogenous eczema which localisation depends on intimate contact with the garment and often seen in skin folds. Such reactions are most commonly seen to disperse azo dyes, but other substances present in clothes can occasionally also induce contact allergy with exception of the fibres themselves. Testing for textile dermatitis is recommended using the European baseline series including TDM, Textile series and own material "as is", as well as with extracts made from it. If possible, performing chemical investigation of the textiles which is positive on patch testing can prove clinical relevance of positive tests and find new emerging allergens.

\section{Compliance with Ethical Standards}

\section{Conflict of Interest}

Cecilia Svedman declares that she has no conflict of interest, Malin Engfeldt declares that she has no conflict of interest, Laura Malinauskiene declares that she has no conflict of interest.

\section{Human and Animal rights and Informed Consent}

This article does not contain any studies with human or animal subjects performed by any of the authors.

Open Access This article is distributed under the terms of the Creative Commons Attribution 4.0 International License (http://creativecommons.org/licenses/by/4.0/), which permits unrestricted use, distribution, and reproduction in any medium, provided you give appropriate credit to the original author(s) and the source, provide a link to the Creative Commons license, and indicate if changes were made.

\section{Publisher's Note}

Springer Nature remains neutral with regard to jurisdictional claims in published maps and institutional affiliations.

\section{References and Recommended Reading}

Papers of particular interest, published recently, have been highlighted as:

- Of importance

1. Hassan MM, Carr CM. A critical review on recent advancements of the removal of reactive dyes from

dyehouse effluent by ion-exchange adsorbents. Chemosphere. 2018;209:201-19. 
2. Kandelbauer A, Gübitz G. Bioremediation for the decolorization of textile dyes - a review. In: Environmental chemistry: green chemistry and pollutants in ecosystems, 1 edn. Berlin [u.a.]: Springer; 2005. p. 269-288.

3. Luongo G, Iadaresta F, Moccia E, Östman C, Crescenzi C. Determination of aniline and quinoline compounds in textiles. J Chromatogr A. 2016;1471:11-8.

4. Luongo G, Thorsen G, Osman C. Quinolines in clothing textiles-a source of human exposure and wastewater pollution? Anal Bioanal Chem. 2014;406:2747-56.

5. Nguyen T, Saleh MA. Detection of azo dyes and aromatic amines in women undergarment. J Environ Sci Health A Tox Hazard Subst Environ Eng. 2016;51:74453.

6. Golka K, Kopps S, Myslak ZW. Carcinogenicity of azo colorants: influence of solubility and bioavailability. Toxicol Lett. 2004;15(151):203-10.

7. Bhatia R, Sharma VK. Occupational dermatoses: an Asian perspective. Indian J Dermatol Venereol Leprol. 2017;83:525-35.

8. Chen YX, Gao BA, Cheng HY, Li LF. Survey of occupational allergic contact dermatitis and patch test among clothing employees in Beijing. Biomed Res Int. 2017;2017:3102358-10. https://doi.org/10.1155/ 2017/3102358.

9. Ramos Pinheiro R, Borges AS, Brasileiro A. Textile allergic contact dermatitis caused by occupational exposure-an overlooked condition. Contact Dermatitis. 2018;79:323-4.

10. Le Coz C-J. Clothing. In: Johansen JD, Frosch PJ, Lepoittevin J-P, editors. Contact dermatitis. 5th ed. Berlin: Springer-Verlag; 2011. p. 793-819.

11. Malinauskiene L, Bruze M, Ryberg K, Zimerson E, Isaksson $\mathrm{M}$. Contact allergy from disperse dyes in textiles: a review. Contact Dermatitis. 2013;68:65-7.

Review on contact allergy to disperse dyes.

12. Zallmann M, Smith PK, Tang MLK, et al. Debunking the myth of wool allergy: reviewing the evidence for immune and non-immune cutaneous reactions. Acta Derm Venereol. 2017;97:906-1.

Review on present knowledge on wool as a possible cause of contact dermatitis.

13. Gonzalez de Olano D, Subiza JL, Civantos E. Cutaneous allergy to cotton. Ann Allergy Asthma Immunol. 2009; 102:263-4.

14. Thomas KS, Bradshaw LE, Sach TH, et al. Randomised controlled trial of silk therapeutic garments for the management of atopic eczema in children: the CLOTHES trial. Health Technol Assess. 2017;16:1-260.

15. Vandevenne A, Morren MA, Goossens A. Immunological contact urticaria caused by a silk shirt in an atopic patient. Contact Dermatitis. 2015;72:240-1.

16. de Groot AC, Maibach HI. Does allergic contact dermatitis from formaldehyde in clothes treated with durable-press chemical finishes exist in the USA? Contact Dermatitis. 2010;62:127-36.
17. Kiracofe EA, Zirwas MJ. Formaldehyde in textiles-what dermatologists need to know about the relationship to contact dermatitis: a review of the US Government Accountability Office's Report to Congressional Committees. J Am Acad Dermatol. 2012;67:313-4.

18. Hamnerius N, Pontén A, Mowitz M. Textile contact dermatitis caused by octylisothiazolinone in compression stockings. Contact Dermatitis. 2018;78:419-21.

19. Aerts O, Goossens A, Lambert J, Lepoittevin JP. Contact allergy caused by isothiazolinone derivatives: an overview of non-cosmetic and unusual cosmetic sources. Eur J Dermatol. 2017;27:115-22.

20. Windler L, Height M, Nowack B. Comparative evaluation of antimicrobials for textile applications. Environ Int. 2013;53:62-73.

21. Umekoji A, Fukai K, Sowa-Osako J, Manabe M, Kikugawa M, Ishii K, et al. Allergic contact dermatitis caused by the preservative 4,5-dichloro-2-n-octyl-4isothiazolin-3-one in black trousers. Contact Dermatitis. 2016;75:326-8.

22. Svedman C, Zimerson E, Bruze M. Allergic contact dermatitis caused by benzanthron in a pair of trousers. Contact Dermatitis. 2014;71:54-64.

23. Aerts O, Duchateau N, Lambert J, Bechtold T. Sodium metabisulfite in blue jeans: an unexpected cause of textile contact dermatitis. Contact Dermatitis. 2014;70:183-92.

24. Fowler JF. Formaldehyde as a textile allergen. Curr Probl Dermatol. 2003;31:156-65.

25. O'Quinn SE, Kennedy CB. Contact dermatitis due to formaldehyde in clothing textiles. JAMA. 1965; 194:593-6.

26. Reich HC, Warshaw EM. Allergic contact dermatitis from formaldehyde -releasers. Dermatitis. 2010;21(2):65-7627.

27. de Groot A, Flyvholm MA, Kensen T, et al. Formaldehyde releasers: relationship to formaldehyde contact allergy. Contact Dermatitis. 2009;61:63-85.

28. de Groot AC, Maibach HI. Does allergic contact dermatitis from formaldehyde in clothes treated with durable - press chemical finishes exist in the USA? Contact Dermatitis. 2010;62:127-36.

29. Inese Dubnika Hauksson Contact allergy to formaldehyde Diagnosis and Clinical relevance. Thesis University of Lund; 2014.

30. Nilsson R, Nordlinder R, Wass U, Meding B, Belin L. Asthma, rhinitis, and dermatitis in workers exposed to reactive dyes. $\mathrm{Br}$ J Ind Med. 1993;50:65-70.

31. Estlander T. Allergic dermatoses and respiratory diseases from reactive dyes. Contact Dermatitis. 1988;18:290-7.

32. Malinauskiene L, Zimerson E, Bruze M, Ryberg K, Isaksson $\mathrm{M}$. Textile dyes disperse orange 1 and yellow 3 contain more than one allergen as shown by patch testing with thin layer chromatograms. Dermatitis. 2011;22:335-43.

33. Hunger K. Industrial Dyes: Chemistry, Properties, Application. Weinheim: Willey-VCH Verlag GmbH \& Co; 2003. 
34. Manzini BM, Motolese A, Conti A, Ferdani G, Seidenari S. Sensitization to reactive textile dyes in patients with contact dermatitis. Contact Dermatitis. 1996;34:172-5.

35. Laura Malinauskiene Contact allergy to textile dyes Clinical and experimental studies on disperse azo dyes. Thesis, University of Lund; 2012.

36. The commission of the European communities. Commission Decision of 15 May 2002: establishing the ecological criteria for the award of the Community ecolabel to textile products and amending Decision 1999/178/EC, 2002/372/EC. Off J Eur Commun. 2002;45:L 133.

37. Oeko-Tex Standard 100. 2012. Available at: http:// www.oeko-tex.com/OekoTex100_PUBLIC/content1. asp area $=$ hauptmenue $\&$ site $=$ grenzwerte $\&$ cls $=02$. Last Accessed 20181010.

38. Calnan CD, Wilson HTH. Nylon stocking dermatitis. Br Med J. 1956;147-149.

39. Wong A, Ball N, de Gannes G. Nonpruritic contact dermatitis from disperse blue dyes. Dermatitis. 2011;22:278-80.

40. Seidenari S, Manzini BM, Danese P. Contact sensitization to textile dyes: description of 100 subjects. Contact Dermatitis. 1991;24:253-8.

41. Heratizadeh A, Geier J, Molin S, Werfel T. Contact sensitization in patients with suspected textile allergy. Data of the Information Network of Departments of Dermatology (IVDK) 2007-2014. Contact Dermatitis. 2017;77:143-50.

42. Lazarov A. Textile dermatitis in patients with contact sensitization in Israel: a 4-year prospective study. J Eur Acad Dermatol Venereol. 2004;18:531-7.

43. Narganes LM, Sambucety PS, Gonzalez IR, Rivas MO, Prieto MA. Lymphomatoid dermatitis caused by contact with textile dyes. Contact Dermatitis. 2013;68:62-4.

44. Lisi P, Stingeni L, Cristaudo A, et al. Clinical and epidemiological features of textile contact dermatitis: an Italian multicentre study. Contact Dermatitis. 2014;70:344-50.

45. Seidenari S, Giusti F, Massone F, Mantovani L. Sensitization to disperse dyes in a patch test population over a five-year period. Am J Contact Dermat. 2002;13:101-7.

46. Abdiweli AM, Andersen F. Allergic contact dermatitis caused by textile dyes mimicking atopic dermatitis. Contact Dermatitis. 2017;76:114-28.

47. Goldminz AM, Scheinman PL. A case series of dupilumab-treated allergic contact dermatitis patients.
Dermatol Ther. First published: 24 September 2018. https://doi.org/10.1111/dth.12701.

Interesting study giving useful possible knowledge for the clinician interested in contact allergy.

48.• Isaksson M, Ryberg K, Goossens A, et al. Recommendation to include a textile dye mix in the European baseline series. Contact Dermatitis. 2015;73:15-2.

Gives basic background for patch testing with the Textile Dye Mix now in the baseline series.

49. Ryberg K, Isaksson M, Gruvberger B, Hindsen M, Zimerson E, Bruze M. Contact allergy to textile dyes in southern Sweden. Contact Dermatitis. 2006;54:31321.

50. Ryberg K, Bråred-Christensson J, Engfeldt $\mathrm{M}$, Isaksson M, Lindberg M, Matura M, et al. Patch testing with a textile dye mix in two concentrations - a multicentre study by the Swedish contact dermatitis research. Acta Derm Venereol. 2015;95:427-31.

51. Isaksson M, Ale I, Andersen KE, Diepgen T, Goh CL, Goossens RA, et al. Patch testing to a textile dye mix by the international contact dermatitis research group. Dermatitis. 2015;26:170-6.

52. Isaksson M, Dahlin J. Patch testing with two textile mixes without disperse orange 3 -which one should be used? Contact Dermatitits. 2018;79(suppl 1).

53. Young E, Svedman C, Bruze M. 28 days follow up of patch-test reactions to p-phenylenediamine and pphenylenediamine dihydrochloride: a multicenter study on behalf of EECDRG.

54. Ryberg K, Goossens A, Isaksson M, Gruvberger B, Zimerson E, Nilsson F, et al. Is contact allergy to disperse dyes and related substances associated with textile dermatitis? Br J Dermatol. 2009;160:107-15.

55. Goon AT, Gilmour NJ, Basketter DA, et al. High frequency of simultaneous sensitivity to disperse orange 3 in patients with positive patch tests to para-phenylenediamine. Contact Dermatitis. 2003;48:248-50.

56. Malinauskiene L, Zimerson E, Bruze M, Ryberg K, Isaksson M. Are allergenic disperse dyes used for dyeing textiles? Contact Dermatitis. 2012;67:141-8.

57. Linauskiene K, Zimerson E, Sorensen Ö, et al. Textile dye mix-positive patients: do they react to currently used synthetic textile extracts? Contact Dermatitis. 2018;79(suppl.1):34-5.

58. Bruze M. The use of ultrasonic bath extracts in the diagnosis of contact allergy and allergic contact dermatitis. In: Lachapelle JM, Bruze M, Elsner PU, editors. Patch testing tips, recommendations from the ICDRG. Verlag: Springer; 2013. p. 129-42. 